\title{
Patriarcado, heteronormatividade e misoginia em debate: pontos e contrapontos para o combate à homofobia nas escolas
}

\author{
Zulmira Newlands Borges* \\ Fátima C. V. Perurena* \\ Guilherme Rodrigues Passamani*** \\ Muriel Bulsing ${ }^{* *+4}$
}

Resumo: Este artigo se propõe a analisar alguns conceitos centrais para o debate e a inclusão do tema homofobia nas escolas. Para além de nossas experiências de pesquisa, buscamos uma dimensão mais teórica na abordagem do assunto. Consideramos que, antes mesmo de uma educação voltada para o respeito à homossexualidade e à diversidade sexual, é necessário discutir com os professores as bases das discriminações homofóbicas presentes na sociedade brasileira. Destacamos três pontos que consideramos estratégicos para a discussão do tema: o patriarcado, a heteronormatividade e a misoginia. Tomando como base esses três conceitos, analisamos entrelaçamentos entre eles e a homofobia presente em nossa sociedade.

Palavras-chave: Heteronormatividade, Patriarcado, Misoginia, Homofobia, Escolas.

\begin{abstract}
The purpose of this article is to analyze some central concepts to discuss and include the subject homophobia in schools. Beyond our research experiences, we look for a more theoretical dimension in dealing with the issue. We believe that, even before an education aimed at respect to homosexuality and sexual diversity, it is necessary to discuss with teachers the basis of homophobic prejudice prevailing in Brazilian society. We highlight three points considered by us as strategic to deliberate about the subject: patriarchy, misogyny and heteronormativity. Based on these three concepts, we analyze interlacements between them and the homophobia present in our society.
\end{abstract}

Keywords: Heteronormativity, Patriarchy, Misogyny, Homophobia, Schools.

\footnotetext{
* Professora associada IV do Programa de Pós-Graduação em Ciências Sociais da UFSM, doutora em Antropologia Social (UFRGS) e pós-doutora em Educação (FACED/UFRGS). Email: zulmiraborges@gmail.com

** Professora associada II do Programa de Pós-Graduação em Ciências Sociais da UFSM, doutora em Sociologia (PUC-SP) e pós-doutora em Sociologia. E-mail: perurena@terra.com.br

*** Professor assistente II do curso de Ciências Sociais da UFMS - CPNV. Doutorando do Programa de Pós-Graduação em Ciências Sociais da Universidade Estadual de Campinas. Email: grpsociais@hotmail.com

**** Bacharel em Ciências Sociais e mestranda do Programa de Pós-Graduação em Ciências Sociais da UFSM.
} 
Patriarcado, heteronormatividade e misoginia em debate: pontos e contrapontos para o combate à homofobia nas escolas.

Este artigo se enquadra nos processos de reconhecimento de direitos específicos ligados à expressão e ao exercício da sexualidade. Apresentaremos reflexões baseadas especialmente em nossas pesquisas realizadas a partir da criação do programa Brasil sem Homofobia (MEC/SECAD). O programa foi criado pelo governo federal, em 2004, como "estratégia de mobilização e inclusão social e educacional". Nossas ponderações concentram-se especialmente na forma de programar e discutir ideias de respeito à diversidade sexual e de combate à homofobia no ambiente escolar. Chamaram-nos atenção as queixas das professoras sobre a falta de suporte e orientação das secretarias de educação e das direções das escolas para a discussão de gênero e sexualidade. Quando ocorre, a única dimensão possível de abordagem do tema da sexualidade na escola é a biológica, tratando exclusivamente os problemas relativos à sexualidade. $\mathrm{O}$ tema da sexualidade, como uma dimensão da saúde humana e como um direito que deve ser usufruído com prazer, respeito e responsabilidade, é raramente discutido. O assunto da homossexualidade é praticamente inexistente, e o preconceito é fortalecido pela invisibilidade. Há escolas e professoras do interior do Rio Grande do Sul que chegam a afirmar que ali não existe esse tipo de problema, claramente demonstrando a invisibilidade, o preconceito e a homofobia que existe em todo o país. Aliado à falta de material didático, o medo de incitar ou estimular a sexualidade ainda persiste. As professoras que abordam o tema na área de humanas sofrem pela falta de amparo e pelo preconceito dos alunos. Por isso, argumentamos ao longo deste artigo que é necessário refletir sobre os entrelaçamentos da homofobia com a heteronormatividade, o patriarcado e a misoginia. Acreditamos que a homofobia é tanto mais forte, disseminada e persistente quanto mais inquestionável for a heteronormatividade, o patriarcado e a misoginia.

O objetivo deste artigo é conduzir a discussão para elementos anteriores ao surgimento do conceito de homofobia, mas que dão base e possibilitam a sua construção. Dissecando e escrutinando os conceitos de patriarcado, heteronormatividade e misoginia, analisamos os entrelaçamentos dessas estruturas de pensamento presentes em nossa sociedade. Em seguida, exploramos caminhos possíveis para discutirmos a heteronormatividade nas escolas. Considera-se a escola como um espaço de práticas sociais imerso em relações de poder. Casos de discriminação e de intolerância foram relatados constantemente em nossas pesquisas anteriores. Propomos discutir alguns pontos e contrapontos para o debate da homofobia nas escolas.

Apontaremos, aqui, pelo menos dois pontos que são constantemente referidos nas pesquisas e que serão abordados ao longo do texto. O primeiro deles é a falta de apoio da comunidade escolar, indicada pelas professoras, já que existe um medo de incitar e estimular a sexualidade na escola. Por isso, quando esta é colocada em pauta nas salas de aula, é sempre a partir dos prismas dos problemas de saúde, risco de aids, DST e gravidez na adolescência. De fato, a sexualidade é um dos aspectos da vida e da saúde, e não há risco de incitar ou estimular mais do que ela já o é pela mídia e pelos meios de comunicação, pelas músicas que as crianças cantam e por tudo que elas assistem nas ruas, nos parques, nas praças sobre a tal sexualidade que não pode ser estimulada na escola. Aprende-se sobre 
Zulmira Newlands Borges

Fátima C. V. Perurena

Guilherme Rodrigues Passamani

Muriel Bulsing

gênero e sexualidade em todos os espaços e em todos os momentos. Ensina-se, direta ou indiretamente, pelo olhar, pelo silenciamento, pelos sorrisos e pelas repreensões ou advertências. Mas é preciso ainda colocar em pauta e como tema transversal nas escolas a questão da sexualidade como um direito, que deve ser usufruído com responsabilidade e com respeito, por si e pelo/a pretendente ou parceiro/a. O que queremos argumentar é que é possível ensinar sobre sexualidade em um contexto de construção de cidadania e de direitos humanos e não apenas de sexo e de doenças. Por isso, consideramos fundamental discutir sobre patriarcado, misoginia e heteronormatividade antes de falar em homofobia.

Outro ponto constantemente referido são as dificuldades de tratar o tema da sexualidade pela falta de material didático. Acreditamos que a música, a literatura brasileira, as piadas, as crônicas e as poesias, os desenhos infantis, o cinema, enfim, tudo pode se tornar material didático para iniciar a discussão sobre sexualidade. A questão não é exatamente o material didático e, sim, o argumento central que deve orientar a discussão sobre o tema na sala de aula. Alegamos que é preciso questionar as bases do pensamento. Questões muito profundas, históricas e arraigadas devem ser repensadas. Para isso, talvez não seja necessário produzir um material específico sobre o assunto sexualidade, ou homofobia, ou homossexualidade, ou bissexualidade, mas partir do pressuposto de que é necessário olhar para a nossa lógica heteronormativa e colocá-la em discussão e relativizar essa lógica através da história e da antropologia. Também é preciso olhar para as bases do patriarcado e da misoginia. A escola deve construir cidadãos que se respeitam e que conseguem viver em sociedade, sabendo que cada indivíduo tem os mesmos direitos que o outro.

\section{Primeiras discussões - Gênero e patriarcado}

Para iniciar nossa discussão, destacamos a tese de Heleieth Safiotti (2004, 2008), para quem os humanos nascem marcados por três grandes subestruturas sociais - classe, etnia e gênero -, e a elas não há quem fuja. Nesse sentido, para fins de análise, isolamos apenas uma dessas três categorias (o gênero), mas compreendemos que os humanos, seres sociais que são, sempre serão uma totalidade multifacetada em que classe, etnia e gênero se mesclam de tal forma que é praticamente impossível ignorar um ou outro. Daremos precedência às questões de gênero pelo fato de a temática proposta estar mais diretamente ligada a ele, mas também tendo como pano de fundo, a compor aquela totalidade, a classe e a etnia.

Embora o conceito de gênero apresente um caráter polissêmico, não se pode negar que hoje há certo consenso (o único) no que se refere ao fato de ele ser um construto social, ou seja, é a construção social do masculino e do feminino. E isso se deve a determinadas discussões que foram travadas por muitas correntes teóricas feministas na tentativa de desnaturalizar as desigualdades entre homens e mulheres. Assim, inicialmente, e até mesmo para marcar um posicionamento político (sempre lembrando a máxima de que "o pessoal é político"), fazemos questão de enfatizar o caráter eminentemente social do gênero, na tentativa de negar essencialismos naturalizantes.

Latitude, Vol. 07, nº 1, pp. 61-76, 2013. 
Patriarcado, heteronormatividade e misoginia em debate: pontos e contrapontos para o combate à homofobia nas escolas.

Aqui no Brasil, o artigo de Joan Scott (1990) fez história, e ainda é referência, como um dos mais significativos textos advogando a causa da relação umbilical entre gênero e construção social. Por outro lado, do ponto de vista metodológico/epistemológico, não se pode, também, cair no construcionismo radical. Não há como, querendo cair fora do cartesianismo dualista, entender gênero apenas através do olhar do social. Assim, concordamos com Saffioti:

O gênero, socialmente construído, se articula ao sexo, situado na esfera ontológica orgânica. O pensamento cartesiano separou radicalmente o corpo da psique, a emoção da razão, gerando verdadeiro impasse. Efetivamente, se a cultura dispõe de uma enorme capacidade para modelar o corpo, este último é o próprio veículo da transmissão do acervo cultural acumulado ou, mais simplesmente, das tradições. (2008, p. 154).

Mesmo reconhecendo o enorme serviço que o conceito de gênero prestou, e presta, às discussões feministas - principalmente hoje -, não se pode dar conta de problemática tão complexa apenas com o seu uso. Nesse sentido, entende-se

[...] a história como processo, admitindo a utilização do conceito de GÊNERO para toda a história, como categoria geral, e o conceito de PATRIARCADO como categoria específica de determinado período, ou seja, para os seis ou sete milênios mais recentes da história da humanidade. (SAFFIOTI, 2004, p. 45).

Evidentemente que aqui não estamos nos referindo à Idade Antiga quando, por exemplo, o patriarca detinha o poder de vida e morte sobre sua mulher e filhos. Com efeito, o patriarcado, sendo ele mesmo a própria sociedade, transformou-se. Os direitos humanos avançaram sobremaneira, no entanto basta ler/ver o noticiário para observar o quanto, de fato, o patriarcado vigora - homens continuam matando suas companheiras, violentando-as de todas as maneiras, deixando-as vivas, mas muitas vezes tetraplégicas, sem falar nos males psicológicos de toda ordem deixados não só pela violência física propriamente dita como também pela violência psicológica.

De outra forma, como explicar o abuso/estupro quando se sabe que em torno de $71 \%$ das meninas violentadas sexualmente o são pelos seus próprios pais biológicos ou por homens pertencentes à família da vítima? No Brasil, são homens que estão na direção de veículos automotivos que causam morte - a eles próprios e aos ocupantes de outros veículos, e cuja hipótese principal, em termos de relações de gênero, está no patriarcado (PERURENA; SANDALOWSKI; MAIA, 2011). Também a homofobia, tema deste trabalho, tem no patriarcado uma de suas origens. Não se tem notícia de mulheres agredindo gays, coletiva ou 
individualmente. Por outro lado, os exemplos de agressões de homens sobre as mulheres e de homens para com outros homens seriam infindáveis.

Rigorosamente, o que as feministas pretendiam, na década de 1970, era denunciar a dominação sofrida pelas mulheres e exercida pelos homens, em uma proposta eminentemente política, mas que deixava margem para questionamentos teóricos. Patriarcado era um conceito vinculado ao método weberiano, que por sua vez compreendia aquele ancorado na economia doméstica, separando-o do Estado. O entendimento aqui adotado não compartilha da proposta teórica weberiana, mas compreende que o político, o econômico e o social são uma coisa só - a sociedade na sua totalidade, sem estilhaçamentos.

É importante esclarecer - visto que normalmente os exemplos do que é o patriarcado estão afeitos à esfera doméstica - que o contrato sexual faz parte do contrato social. Segundo alguns teóricos, sendo o patriarcado apenas ideologia, ele não se remete ao mundo público. Não há como negar a prevalência de atividades privadas ou íntimas na esfera da família, mas o Estado é quem as normatiza, ou seja, contrato social e contrato sexual, pode-se dizer, são a mesma coisa, um informando o outro. Novamente, público e privado mesclam-se, sendo impossível entender um sem o outro.

Carole Pateman (1993) esclareceu essa questão, pondo fim à ideia de que a modernidade, ao instituir o Estado liberal, acabou com o patriarcado, como queria Locke. Para essa autora, paralelamente ao contrato social, instituiu-se o contrato sexual, passando a vigorar, então, o "direito patriarcal moderno", legitimando o direito sexual do acesso masculino aos corpos femininos. Muito contribuiu para a lógica do patriarcado a crescente valorização e a institucionalização da monogamia como valor fundamentado em grande parte na Igreja Católica e na valorização da família composta por pai, mãe e filhos. O fundamento monogâmico garantiu também a consolidação da propriedade privada e a transmissão de bens de pai para filhos.

A título de esclarecimento, aqui se entende o conceito de patriarcado da forma em que o formulou Allan Johnson (1997, p. 4-5):

[...] patriarcado não é simplesmente outra maneira de dizer 'homens'. Patriarcado é um tipo de sociedade, e uma sociedade é mais que um conjunto de pessoas... Uma sociedade é patriarcal na medida em que é dominada por machos, identificada com machos e centrada nos machos.

É preciso ver a quem serve manter apenas o uso do conceito de gênero, e pensar se este, não sendo neutro (porque em ciência nada é neutro), é bem menos neutro que o conceito de patriarcado. Insistindo-se apenas no uso daquele, esconde-se o que verdadeiramente está por trás - a máquina patriarcal bem azeitada, operando sem parar, ao estilo de tempos modernos, tão bem exposto por Charles Chaplin.

Pelo exposto até agora, propomos que os conceitos de gênero e patriarcado sejam utilizados simultaneamente, posto que o primeiro é bem mais abrangente 
Patriarcado, heteronormatividade e misoginia em debate: pontos e contrapontos para o combate à homofobia nas escolas.

que o segundo, dando conta de cobrir toda a história da humanidade. O patriarcado, segundo Gerda Lerner (1986) e Allan Johnson (1997), tem datação histórica, cobrindo os últimos seis ou sete milênios da história dos humanos no planeta. Com efeito, o conceito analítico gênero permite que se advogue o fim ou a diminuição das desigualdades entre machos e fêmeas. O conceito de patriarcado mostra o quanto ainda se pode ver/lutar contra a dominação/exploração de mulheres por homens. Assim, concordando com Saffioti, o conceito de patriarcado não tem a pretensão

[...] da generalidade nem da neutralidade, e deixando, propositadamente explícito, o vetor da dominaçãoexploração. Perde-se em extensão, porém, se ganha em compreensão. Entra-se, assim, no reino da História. Trata-se, pois, da falocracia, do androcentrismo, da primazia masculina. É, por conseguinte, um conceito de ordem política. E poderia ser de outra ordem se o objetivo das(os) feministas consiste em transformar a sociedade, eliminando as desigualdades, as injustiças, as iniquidades, e instaurando a igualdade? (SAFFIOTI, 2008, p. 177).

Os desdobramentos do patriarcado perpassam diferentes períodos históricos e ganham novas roupagens que se adaptam aos diferentes tempos. Se pensarmos a sociedade contemporânea, não é difícil perceber os traços patriarcais travestidos de misoginia ${ }^{1}$ e heteronormatividade. Os valores que constroem o pensamento misógino e heteronormativo estão assentes em pressupostos patriarcais, sobretudo no que diz respeito à subjugação do outro a uma condição não apenas manifesta, mas também latente de inferioridade, desprezo e humilhação.

\section{Heteronormatividade e homofobia}

Desde as principiantes discussões de gênero até o aporte encorpado da teoria queer, é fundamental a contribuição do movimento feminista, o qual é importante inclusive para pensar a homofobia. Aprofundando o debate feminista, a teoria queer, nas palavras de Richard Miskolci (2009), entende a sexualidade como um dispositivo de poder. Esse poder é historicamente estabelecido por meio de diversos discursos e diferentes práticas sociais.

1 A misoginia é um aspecto central da violência contra as mulheres e da violência homofóbica. Ela se manifesta em várias formas diferentes de piadas, pornografia e violência. Até os padrões excessivos e inalcançáveis de beleza podem ser enquadrados como um aspecto da misoginia da nossa cultura ocidental moderna. Em resumo, a misoginia está relacionada à desvalorização do feminino e, em sua versão mais radical, ao ódio ou desprezo ao feminino. 
Zulmira Newlands Borges

Fátima C. V. Perurena

Guilherme Rodrigues Passamani

Muriel Bulsing

Assim, as noções de certo e errado, em termos de gênero, sexualidade e orientação sexual, são atributos estabelecidos pelos valores culturalmente construídos; valores estes que seguem uma orientação. No mais das vezes, tal orientação fala de um lugar de poder, um lugar que é social, político, filosófico e religioso.

Esse lugar que estabelece as normas e as dispõe como destinos manifestos, no caso da sociedade ocidental, construiu aquilo que se convenciona chamar de heteronormatividade, ou seja, torna os valores associados à heterossexualidade como os pressupostos que regram a sociedade e devem ser compulsórios aos indivíduos.

Miskolci (2009) mostra, em outras palavras, que a heterossexualidade é encarada pela sociedade ocidental, em grande medida cristã, como algo natural. Assim, desdobra-se dela todo um rol de expectativas e desejos, justamente, nas palavras do autor, porque ela seria o fundamento da sociedade (MISKOLCI, 2009, p. 156).

Como destacado por Michel Foucault (2005), a nossa sociedade assenta-se na necessidade de formar e disciplinar os sujeitos a fim de que sejam heterossexuais e difundam os valores associados à heterossexualidade. Em tempo, é preciso que fique claro que a heteronormatividade abarca a sociedade como um todo, portanto todos estão sujeitos aos seus pressupostos, pois ela é uma categoria que estrutura e fundamenta a dinâmica social.

A realidade que se tem hoje é devedora, em grande medida, de uma sequência de acontecimentos patologizantes e medicalizantes, a rigor, assentados no século XIX. Foi na segunda metade desse século que houve uma atenção para os fenômenos da sexualidade, em que se instauraram mecanismos que estabelecem as verdades sobre o sexo e, igualmente, começaram a nomear os sujeitos sexualizados. Nasceu aí, por exemplo, o homossexual. A heterossexualidade tornou-se a única possibilidade saudável de viver e experienciar a sexualidade. E, segundo Guacira Lopes Louro (2009), o corpo passou a ser compreendido como a causa e a justificativa das diferenças. Diferenças que confundiam e relacionavam, de forma causal e interdependente, sexo, gênero e sexualidade.

As práticas sexuais entre pessoas do mesmo sexo são recorrentes na história, desde a antiguidade, ou desde que existem registros históricos. No entanto tais práticas não mereciam qualquer atenção, pois eram apenas formas de experimentação do prazer e da sexualidade. Não existia um sujeito homossexual. Esse sujeito, como lembra Foucault (2005), é do século XIX.

O homossexual, então, a partir do surgimento de uma scientia sexualis, não era mais um pecador, um doente ou um criminoso. Ele era outro ser, outra espécie de indivíduo. Sobre ele recaiu toda a gama de desconfiança possível, em grande medida, motivada pela necessidade de fortalecer a norma, heterossexual, cujas práticas não deveriam ser tão institucionalizadas assim, tendo em vista que é desnecessário convencer a população sobre o que já é consenso. Nesse processo de normatização da sexualidade, construiu-se uma série de juízos morais sobre o homossexual como uma figura maléfica, marginal e passível de perverter a ordem social.

Latitude, Vol. 07, nº 1, pp. 61-76, 2013. 
Patriarcado, heteronormatividade e misoginia em debate: pontos e contrapontos para o combate à homofobia nas escolas.

Louro (2009) produz uma reflexão interessante nesse sentido. Ainda que o homossexual e a homossexualidade sejam razão de escárnio, essas categorias se tornam imprescindíveis para justificar e normatizar a heterossexualidade. Ou seja, a heterossexualidade só tem sentido em função da homossexualidade. São categorias interdependentes. Mas, segundo a teoria queer, elas não esgotam as possibilidades de expressão da sexualidade. Como dito acima, não há heteronormatividade dada. Ela se constrói e se reconstrói todos os dias. O que tem se observado no presente século é uma reorientação da compreensão da heteronormatividade, isto é, seus contornos que antes se preocupavam em resguardar a heterossexualidade dos perigosos diferentes - em termos de normalidade ou patologia e, portanto, no âmbito da saúde - agora começam a, além disso, reforçar um discurso de ódio e de violência sobre essas categorias, especialmente para com o segmento LGBT (lésbicas, gays, bissexuais e transgêneros). Esse sentimento, traduzido em ações concretas, é comumente chamado de homofobia.

O vocábulo homofobia afere uma hostilidade aos homossexuais. Desde um ponto de vista homofóbico, os homossexuais necessitam ser estabelecidos como dissidentes em relação à ordem estabelecida; leia-se à ordem heterossexual. Figuram nesse cenário como inferiores e anormais (BORRILLO, 2010). Estamos diante de um conceito bastante jovem. O termo homofobia data dos anos 1970. Segundo Daniel Borrillo (2010), a palavra foi cunhada por K. T. Smith em 1971. Smith fazia uma pesquisa na qual tentava compreender a personalidade daqueles que discriminavam homossexuais, e homofobia aparece no artigo resultante dessa pesquisa. Um ano depois, em 1972, G. Weinberg foi quem definiu homofobia com mais clareza, pela primeira vez. Para ele, essa palavra denotava "o receio de estar com um homossexual em um espaço fechado e, relativamente aos próprios homossexuais, o ódio por si mesmo" (BORRILLO, 2010, p. 21).

Daniel Borrillo (2010), em seu livro - já clássico, embora muito recente -, demonstra como a homofobia é um tipo específico de preconceito/sentimento/prática gestado e resultante de um conjunto de emoções, condutas e ideologias cujo princípio norteador é a construção de uma ética moral que despreze os homossexuais. A criação dos homossexuais como figuras dissidentes, destoantes ou diferentes é produto de um discurso heteronormativo que se encarrega de estabelecer hierarquias, não apenas no mundo nos desejos, mas, sobretudo, no mundo da moral, da religião e, por que não, da política.

Nesse sentido, o caso brasileiro é bastante emblemático. A população LGBT ainda se vê excluída de uma série de direitos vistos, inclusive, como universais. Há uma gama de direitos ainda negados aos homossexuais brasileiros que os colocam em situação de completa vulnerabilidade social. O Estado brasileiro, dessa forma, infringindo a própria laicidade conquistada constitucionalmente, afronta os direitos humanos ao considerar os homossexuais como cidadãos de segunda categoria, algumas vezes motivado por crenças religiosas específicas de determinadas igrejas (RIOS, 2002).

Como bem pontua Daniel Borrillo (2010), ao problematizar o caso francês em relação à legislação pró-LGBT, as leis a favor da população LGBT são sempre leis de exceção, isto é, trata-se de casos particulares, especiais. Não há um avanço 
Zulmira Newlands Borges

Fátima C. V. Perurena

Guilherme Rodrigues Passamani

Muriel Bulsing

efetivo rumo à equidade. Essas reivindicações por equidade acabam esbarrando na tradição, na religião (difusora de uma moral social) e nos costumes. Logo, quando existem, os avanços são lentos.

Na prática, no Brasil de hoje, para ter o seu direito de cidadão respeitado, em termos de saúde, estado civil e constituição de família através da adoção, os casais homossexuais precisam lutar judicialmente por ele. A constituição afirma a igualdade, mas os valores e a prática social demonstram uma realidade baseada em valores homofóbicos. É preciso repensar tudo isso desde cedo, e o melhor lugar para proporcionar uma mudança, em médio prazo, ainda é a escola.

Se aos heterossexuais a sexualidade é só mais uma dimensão de sua complexa teia identitária, aos homossexuais ela acaba tornando-se a sua referência, não apenas para compreender ou explicar os seus desejos, mas para justificar a sua condição de uma cidadania pela metade, ou de uma subcidadania. As sexualidades não referendadas pela heteronormatividade são encaradas como um desvio da norma, portanto passíveis de não terem qualquer respaldo legal, social e até humano (PASSAMANI; MAIA, 2011).

As questões que se apresentam a serem resolvidas são complexas e exigem comprometimento de diferentes instâncias da sociedade. Há poucos anos as mulheres, os negros e os indígenas eram marcados pela diferença e exclusão. Essas pautas recentemente dão sinais de mudança. No entanto, aos homossexuais, ainda continuam a existir barreiras que os impedem de desfrutar da cidadania plena. Uma nova ética, mais plural e humanista, passa necessariamente por discutir as bases do processo de ensino-aprendizagem. Por isso, tais questões, necessariamente, devem estar nas salas de aula, sendo debatidas de maneira séria, oxigenada e laica.

\section{Homossexualidade, misoginia e homofobia}

Homossexualidade, misoginia e homofobia são aspectos fortemente entrelaçados e constituídos historicamente. Embora seja impossível estabelecer uma hierarquia entre eles, para fins deste artigo consideramos que a misoginia precede a visão contemporânea da homossexualidade e constitui-se enquanto um dos pilares da homofobia. A estratégia de desvalorização das mulheres e o esforço em subjugá-las e mantê-las longe das esferas de decisão perpassou inúmeras culturas e governos. Segundo Scott (1993, p. 25):

A ligação entre os regimes autoritários e o controle das mulheres tem sido observada, mas não foi estudada com profundidade. Seja num momento crítico para a hegemonia jacobina durante a Revolução Francesa, seja na hora em que Stálin apoderou-se da autoridade de controle, ou na época da implementação da política nazista na Alemanha, ou ainda no triunfo do Aiatolá Khomeiny no Irã, em todas essas circunstâncias, os dirigentes emergentes legitimavam a dominação, a força, 
Patriarcado, heteronormatividade e misoginia em debate: pontos e contrapontos para o combate à homofobia nas escolas.

\begin{abstract}
a autoridade central e o poder soberano identificando-os ao masculino (os inimigos, os "outsiders", os subversivos e a fraqueza eram identificados ao feminino), e traduziam literalmente esse código em leis (proibindo sua participação na vida política, tornando o aborto ilegal, proibindo o trabalho assalariado das mães, impondo códigos de vestuário a mulheres) que colocavam as mulheres em seu lugar. Essas ações e a época de sua realização têm pouco sentido em si mesmas. Na maioria dos casos, o Estado não tinha nada de imediato ou nada de material a ganhar com o controle das mulheres. Essas ações só podem adquirir sentido se elas são integradas a uma análise da construção e da consolidação do poder. Uma afirmação de controle ou de força tomou a forma de uma política sobre as mulheres.
\end{abstract}

Partindo de Scott (1993), argumentamos que há historicamente a identificação do masculino com qualidades e aspectos positivos e superiores, ao mesmo tempo em que o feminino é visto como perigoso, subversivo e fraco. A nosso ver, misoginia e patriarcado são dois conceitos interdependentes, sendo impossível a sobrevida de um sem a presença do outro. O patriarcado, enquanto estrutura de pensamento, só pode existir difundindo a misoginia que lhe dará respaldo e legitimidade. Para alguns, a "homofobia é similar à misoginia, pelo menos no que diz respeito aos homens sexualmente passivos ou que apresentam um comportamento feminino, independente de suas preferências sexuais, da mesma forma que as mulheres que apresentam um comportamento masculinizado" (TORRÃO FILHO, 2005, p. 147).

Algumas pesquisas sobre homofobia nas escolas demonstraram que a violência homofóbica é proporcional à transgressão de gênero:

Se podemos tomar as culturas de gênero como potecializadoras de vulnerabilidade é importante pensar que existe uma hierarquia de valores dentro da própria homofobia que é capaz de ser mais ou menos violenta conforme a transgressão ao comportamento de gênero que é socialmente esperado. Nesse momento, parece ser mais aceitável um casal homossexual, seja feminino ou masculino, se ambos os parceiros comportam-se dentro das expectativas de gênero do seu sexo, compondo casais de homens másculos e mulheres femininas e, principalmente, sem manifestações de afeto em público. Nesse sentido, a homofobia no Brasil recebe um reforço cultural que é a desvalorização de tudo que é feminino ou coisa de mulher. Os homens que se aproximam de um comportamento socialmente identificado como feminino serão fortemente vigiados, discriminados e, certamente, 
Zulmira Newlands Borges

Fátima C. V. Perurena

Guilherme Rodrigues Passamani

Muriel Bulsing

sofrerão vários tipos de penalidades na escola. (BORGES; MEYER, 2008, p. 66).

As pesquisas demonstram que o crime maior, para a sociedade brasileira, não é exatamente ser homossexual ou bissexual. Há imensa diversidade de práticas sexuais socialmente aceitas, e a criatividade humana é inesgotável nesse campo. $\mathrm{O}$ problema, de fato, se coloca no campo das disputas de significados e regras culturais socialmente aceitas e dos valores e crenças morais historicamente constituídos. Há - para os homofóbicos - uma traição aos valores culturais e às regras estruturantes do pensamento quando uma criança de sexo masculino se identifica com uma performance de gênero feminino. No exemplo a seguir, vemos uma situação de violência simbólica que ilustra muito bem a desvalorização do feminino e das tarefas femininas, sendo vistas com tal grau de desqualificação que podem ser usadas como uma punição para a criança que ousa transgredir a norma que impõe um destino e uma performance masculinas a um corpo com aparato biológico masculino. No artigo de Borges e Meyer (2008, p. 70), vemos relato exemplar dessa situação misógina e homofóbica:

Uma professora relatou o caso de um aluno seu que sofria fortes discriminações e vigilância da mãe e das professoras, pois aos sete anos gostava de se maquiar e usar roupas femininas e, embora os colegas não o descriminassem em função disso, a família e as professoras o repreendiam constantemente. Segundo o relato da professora, "a mãe repreende e ao mesmo tempo incita o filho de outras formas, por exemplo: se tu quer ser bicha, então tu vai lavar a louça e lavar o chão e arrumar casa, porque isso é serviço de mulher. E como aqui só tem uma bicha, tu é que vai fazer." Esta situação familiar descrita pela professora é bem representativa de uma mistura, bastante comum, entre homofobia e misoginia em que, na hierarquia de valores da sociedade brasileira, um homossexual que não transgrida a relação entre sexo e gênero e se comporte como um homem masculino ou uma mulher feminina é mais aceito do que um homem com características femininas ou uma mulher com aparência masculina. (BORGES; MEYER, 2008, p. 70).

Nesse relato, a mãe obriga o filho - que, segundo ela, "quer ser bicha" - aos serviços domésticos, como se isso fosse uma terrível punição, rebaixando-o na escala social a ocupar tarefas subalternas, como se o fato de a criança se aproximar do imaginário do que vem a ser um comportamento feminino o destinasse a uma

Latitude, Vol. 07, nº 1, pp. 61-76, 2013. 
Patriarcado, heteronormatividade e misoginia em debate: pontos e contrapontos para o combate à homofobia nas escolas.

inferioridade social. Torrão Filho (2005) aponta como é fortemente discriminada em nossa cultura a não continuidade entre sexo e gênero. Onde o feminino é a grande ameaça à heterossexualidade do homem, há um rebaixamento social, pois, ao escolher a feminização, o homossexual ultraja e desrespeita sua natureza e a outros homens. O mesmo ocorre com a masculinidade, que é interdita às mulheres:

De um lado, o feminino é a grande ameaça à heterossexualidade do homem; cada época define a categoria do risco, mas o feminino é sempre a ameaça ao homem. Por outro, a masculinidade é interdita à mulher, pois a mulher no lugar do homem é o "mundo às avessas", a ordem corrompida, a natureza ultrajada. Portanto, homens homossexuais rebaixam seu sexo escolhendo estar abaixo de outros homens; e as mulheres lésbicas, por sua vez, usurpam um poder que não lhes pertence, e ao qual sequer podem usar, já que são desprovidas dos meios da consumação da masculinidade. (TORRÃO FILHO, 2005, p. 143)

Sendo assim, consideramos que patriarcado, heteronormatividade e misoginia são conceitos que se constituíram ao longo da nossa civilização judaicocristã e que precisam ser analisados, dissecados, escrutinados e relativizados por aqueles que irão formar os cidadãos de amanhã. É necessário dar-se conta de que não se pode continuar vivendo a partir de uma lógica e de valores socialmente ultrapassados. É preciso enfrentar a questão, refletindo sobre sua historicidade e contextualização e que, portanto, pode ser alterada e atualizada a partir de novos padrões de pensamento de uma sociedade menos agressiva, menos violenta, mais tolerante, mais democrática, inclusiva e menos homofóbica. A violência contra as mulheres e contra os homossexuais tem recebido maior visibilidade, pois tem ocorrido maior mobilização política e maior luta por direitos, tanto por parte das mulheres quanto dos homossexuais. Mas as bases que constituem essas violências são as mesmas, ou seja, a heteronormatividade, o patriarcado e a misoginia, que precisam ser estudados e combatidos. A escola pode e deve ser um local para se ensinar solidariedade, inclusão, democracia e cidadania.

\section{Possibilidades de discutir a problemática da homofobia nas escolas}

Abordar questões sobre gênero, sexualidade e homofobia, de uma forma geral, já é difícil por si só. Nas escolas torna-se tarefa ainda mais árdua, dada a crescente interferência da moral religiosa, especialmente de alguns setores mais radicais das igrejas neopentecostais. Propomos o uso da arte, da literatura e do cinema para discutir esses temas com professores e alunos. $\mathrm{O}$ foco desses filmes, textos e livros deve sempre ser outras possibilidades de arranjos familiares e de vivências saudáveis e respeitosas da sexualidade humana. Busca-se enfatizar a ideia de saúde sexual não como enquadramento em uma heteronormatividade, mas como a possibilidade de exercer com responsabilidade, respeito, maturidade $\mathrm{e}$ 
Zulmira Newlands Borges

Fátima C. V. Perurena

Guilherme Rodrigues Passamani

Muriel Bulsing

prazer a sua vida sexual. A alternativa que consideramos mais rápida e eficaz é justamente a proposta de realizar ciclos de cinema que abordem essas temáticas. A possibilidade de elencar tais questões em ciclos de cinema pode viabilizar a discussão desses temas ludicamente, de modo sério e democrático, desconstruindo tabus e silenciamentos.

Segundo Portes (2011, p. 1659), a utilização do cinema como arcabouço teórico e metodológico é ferramenta que se utiliza de conceitos provenientes da História Cultural como, por exemplo, os de apropriação e representação de Chartier para tecer análise tanto de imagens e de linguagem cinematográfica quanto da própria historiografia. Tal como Chartier, entendemos que o aprendizado mediado pelas representações cinematográficas auxilia na identificação objetiva de diferentes representações que, por sua vez, dão-se em diferentes lugares e momentos de uma determinada realidade social e que, portanto, é construída, pensada e acionada.

A linguagem cinematográfica, ao dar-se ênfase às representações e relações sociais que constroem identidades de gênero, levando-se em conta contextos interrelacionados como os de relações de poder, etnia, sexualidade e religião, possibilita uma acentuada visibilidade à complexidade na qual os indivíduos estão inseridos em seus mais diversos momentos de vivência e experiência. De Oscar Wilde ainda no século XIX, que já dizia que "a vida imita a arte muito mais do que a arte imita a vida" - a Robert Rosenstone $(1997$, p. 22) - que nos diz que as imagens são capazes de mudar as regras do próprio jogo histórico -, vemos que atualmente a ferramenta cinematográfica tem a potencialidade de ser mais complexa que o próprio texto escrito, devido à grande interação de fenômenos e dimensões nela expostos.

As relações entre cinema e educação nos permitem outro viés teórico e outra abordagem metodológica, evidenciando novos aspectos dos processos sociais que presidem essa interação. Assim, a discussão a partir do cinema aproxima a comunidade de situações, histórias de vida, sofrimentos e experiências que comovem e afetam as pessoas. Essa aproximação com outra realidade e outros modos de vida que o cinema propicia é potencialmente transformadora por possibilitar a desconstrução de estereótipos e pré-conceitos que devem ser analisados e debatidos nas discussões com especialistas após a exibição do filme.

A experiência com o uso do cinema (inserem-se aí os documentários) evidencia o potencial transformador de novas ferramentas educacionais advindas do meio virtual. "Foi assim que os irmãos Lumière realizaram as primeiras tomadas: cenas que testemunhavam a saída de trabalhadores da usina." (PORTES, 2011, p. 1660). O cinema vem sendo utilizado incisivamente como fonte para além do entretenimento mais ou menos desde a década de 1970, pois foi a partir daí que se evidenciou sua capacidade de transgredir pontos e consensos que a sociedade tinha como fixos.

O cinema obriga o espectador a entrar em contato com outra realidade que, por mais fantasiosa que se pareça, poderia ser real - e a verossimilhança por si só tem grande potencial de afetar e comover. Além disso, o cinema propicia um tipo de aproximação entre realidades tão distintas e distantes socialmente que, se deixadas ao acaso, seria impossível acontecer, dada a marginalização e a exclusão de alguns

Latitude, Vol. 07, nº 1, pp. 61-76, 2013. 
Patriarcado, heteronormatividade e misoginia em debate: pontos e contrapontos para o combate à homofobia nas escolas.

grupos sociais. Os temas em ascensão mudam de época para época, mas a inserção do espectador na imagem (som, história, romance etc.) que se desenrola na tela não mudou dramaticamente. Ao contrário, com as novas tecnologias - como o cinema $3 \mathrm{D}$-, cria-se um redimensionamento daquilo que é real e do que é mera criação, mesmo que essa criação seja uma recriação ipsis litteris de uma realidade que não se mostra palpável naquele momento, mas inteiramente sensível.

Discutindo o conceito de homofobia, percebemos que, de um modo geral, refere-se à intolerância gerada pela discriminação contra pessoas que possuem uma orientação afetiva e/ou sexual que se diferencia das opções tidas como comuns - muitas vezes, esse termo comum sendo análogo ao que seria considerado saudável, esperado, respeitado etc. Na Constituição da República Federativa do Brasil de 1988, lê-se explicitamente (art. 3ํ, inciso IV) que é dever e direito do Estado e de cada cidadão promover o bem de todos, indistintamente, sem incorrer com qualquer forma de preconceitos, seja de origem racial, sexual, de idade ou quaisquer outras formas de discriminação. Sendo assim, a homofobia fere os direitos básicos e fundamentais da pessoa humana.

As consequências da prática homofóbica ${ }^{2}$ são demasiadamente desastrosas tanto para aqueles que sofrem diretamente com tal preconceito como para os familiares em geral e, acima de tudo, para a sociedade, que perde muito de seu potencial democrático ao agir com intolerância e desrespeito às vivências e experiências alheias.

No uso de filmes como material didático, é interessante possibilitar aos espectadores observar a homofobia sob a perspectiva daqueles que sofrem diretamente as consequências da discriminação. Uma questão importante para ser analisada é a amplitude da homofobia, cujos efeitos vão desde a violência simbólica, que conforma modos de ser e de se comportar no mundo, restringindo as possibilidades de existência, até a violência física extrema, que destrói e elimina pessoas não conformadas à regra heteronormativa.

Outro ponto que vale a pena ser discutido através de filmes ou da literatura é que a violência homofóbica é diretamente proporcional ao valor moral que supostamente é infringido. Os crimes homofóbicos tendem a ser mais graves ou mais violentos tanto mais o sujeito atacado tenha engendrado uma oposição entre a identidade de gênero e seu corpo biológico. Os gays que dissimulam ou disfarçam a sua homossexualidade são socialmente mais aceitos do que aqueles que se aproximam de uma identidade de gênero oposta à sua natureza biológica. Descortinar a hipocrisia da sociedade pode ser um caminho interessante para orientar os debates. Em algumas situações, os próprios professores e diretores de escolas veem como afronta, má educação e desrespeito o rapaz que vai vestido de mulher. É claro que deve haver acordos sobre o comportamento socialmente aceito, e o que pode ou não na escola deve ser respeitado. Mas as regras precisam valer para todos e não podem fazer diferenças de gênero, classe ou cor.

\footnotetext{
2 Homofobia que ultimamente tem alcançado maior visibilidade no âmbito escolar devido à maior discussão e ao entendimento do conceito de bullying que, resumidamente falando, seriam todos aqueles atos de origem física e/ou psicológica que agridem crianças e jovens que não se enquadram ao padrão considerado tácito pelos demais colegas.
} 
Zulmira Newlands Borges

Fátima C. V. Perurena

Guilherme Rodrigues Passamani

Muriel Bulsing

Outro ponto a ser trabalhado e discutido nas escolas, e de preferência a partir de filmes, é o sofrimento pessoal de constituir-se enquanto sujeito e assumir integralmente sua personalidade e seu desejo. Vale reforçar a importância da escola e de outras instituições de formação que podem contribuir no desenvolvimento do aluno; esferas que possam auxiliar a dar apoio emocional e social aos jovens que estão na fase de experimentações sexuais. Filmes, literatura, obras de arte, biografias e até músicas podem ser pontos de partida para discussões sobre sexualidade e gênero nas escolas.

Na verdade, na adolescência todos passamos por transformações corporais que devem ser discutidas nas escolas, não apenas em termos biológicos, mas em termos sociais, apontando que todos passam por dificuldades e desafios na constituição da própria personalidade e da própria identidade social. Esse processo para todos exige certa dose de coragem para conhecer, aceitar e usufruir as mudanças corporais, emocionais e sociais. De fato, entrar no mundo da vida adulta é desafiante para todos e exige coragem de todos. É necessário reverter a lógica de uma fraqueza moral na assunção da homossexualidade e vê-la dentro do âmbito da sexualidade humana. Independentemente de o sujeito ser hétero ou homossexual, ele/ela deverá se tornar uma pessoa de bem, trabalhador/trabalhadora e cidadão/cidadã. Seja qual for a prática ou a identidade sexual, ele/ela deverá respeitar os parceiros e aprender que a liberdade de um termina quando começa a liberdade do outro. É importante retirar a discussão do âmbito da escolha e colocá-la no âmbito dos direitos humanos e do respeito ao outro e, portanto, comuns a todos os estudantes em formação, independentemente da classe, da cor e da identidade sexual.

\section{Bibliografia}

BORGES, Zulmira Newlands; MEYER, Dagmar Estermann. Limites e possibilidades de uma ação educativa na redução da vulnerabilidade à violência e à homofobia. Ensaio: Avaliação e Políticas Públicas em Educação, Rio de Janeiro, v. 16, n. 58, p. 59-76, mar. 2008.

BORRILLO, Daniel. Homofobia: história e crítica de um preconceito. Belo Horizonte: Autêntica Editora, 2010.

BRASIL. Constituição da República Federativa do Brasil (1988). Disponível em: $<$ http://www.planalto.gov.br/ccivil_03/constituicao/constitui\%C3\%A7ao.htm>.

Acesso em: 10 out. 2011.

FOULCAULT, Michel. História da Sexualidade, v. I: a vontade de saber. São Paulo: Graal, 2005.

JOHNSON, Allan G. The gender knot. Unraveling our patriarchal legacy. Philadelphia: Temple University Press, 1997.

LERNER, Gerda. The creation of patriarchy. New York/Oxford: Oxford University Press, 1986.

LOURO, Guacira Lopes. Heteronormatividade e Homofobia. In: JUNQUEIRA, Rogério (org.). Diversidade sexual na educação: problematizações sobre a homofobia nas escolas. Brasília: Unesco, 2009.

Latitude, Vol. 07, nº 1, pp. 61-76, 2013. 
Patriarcado, heteronormatividade e misoginia em debate: pontos e contrapontos para o combate à homofobia nas escolas.

MISKOLCI, Richard. A Teoria Queer e a Sociologia: o desafio de uma analítica da normalização. Sociologias, Porto Alegre, v. 11, n. 21, p. 150-182, jan./jun. 2009.

PASSAMANI, Guilherme R. Na batida da concha: sociabilidades juvenis e homossexualidades reservadas no interior do Rio Grande do Sul. Santa Maria-RS: EDUFSM, 2011.

- MAIA, Lenine R. Um herói gay: uma análise sobre homofobia, militância e moralidade a partir de Milk - A Voz da Igualdade. In: PASSAMANI, Guilherme R. (org.). Ciclo de Cinema: entre histórias, teorias e reflexões - O direito à diferença. Campo Grande: EDUFMS, 2011.

PATEMAN, Carole. O contrato sexual. São Paulo: Paz e Terra, 1993.

PERURENA, Fátima; SANDALOWSKI, Maricleise; MAIA, Gabriela F. Violência no trânsito: gênero, masculinidades e patriarcado. In: PASSAMANI, Guilherme (org.). (Contra)pontos: ensaios de gênero, sexualidade e diversidade sexual. Campo Grande: EDUFMS, 2011.

PORTES, Isabelle. A "República da Lapa" e o Malandro Yansã: relações entre cinema e história, raça e gênero a partir de Madame Satã (Karim Aïnouz - 2002). In: V INTERNATIONAL CONGRESS OF HISTORY, 2011. Disponível em: $<$ http://www.cih.uem.br/anais/2011/trabalhos/209.pdf>. Acesso em: 14 dez. 2011.

RIOS, Roger Raupp. O princípio da igualdade e a discriminação por orientação sexual. A homossexualidade no Direito Brasileiro e Norte-Americano. São Paulo: Ed. Revista dos Tribunais, 2002.

ROSENSTONE, Robert. El pasado en imágenes: el desafío del cine a nuestra idea de la historia. Barcelona: Ariel, 1997.

SAFFIOTI, Heleieth I. B. Gênero, patriarcado, violência. São Paulo: Editora Fundação Perseu Abramo, 2004.

. A ontogênese do gênero. : STEVENS, Cristina M. T.; SWAIN, Tânia Navarro. A construção dos corpos: perspectivas feministas. Florianópolis: Ed. Mulheres, 2008.

SCOTT, Joan W. Gênero: uma categoria útil para a análise histórica. Recife: SOS Corpo, 1993.

TORRÃO FILHO, Amilcar. Uma questão de gênero: onde o masculino e o feminino se cruzam. Cadernos Pagu, Campinas, n. 24, p. 127-152, jan./jun. 2005. 